\title{
Commentary: Sculpting a heart of stone
}

\author{
Tomasz A. Timek, MD, PhD
}

Surgical septal myectomy effectively and predictably relieves symptomatic left ventricular outflow obstruction (LVOT) associated with hypertrophic cardiomyopathy (HCM) ${ }^{1,2}$ In selected patients without LVOT obstruction, symptomatology may be related to small LV chamber size or mid-ventricular impediment, presenting a greater surgical challenge. The apical myectomy developed by the Mayo group $^{3}$ has shown to be an effective treatment for these patients, although wider experience is lacking. In the current issue of the JTCVS Techniques, Sun and colleagues ${ }^{4}$ present an unusual cohort of 6 patients who initially underwent septal myectomy and subsequently required an apical approach to address small LV cavity size and diastolic dysfunction. The authors found that this novel approach resulted in subjective clinical improvement in majority of the patients with concurrent echocardiographic enlargement of LV dimensions. However, confounding clinical pathology and small number of patients hinder definite conclusions.

Although symptomatic improvement is presumably linked to larger LV chamber volume, the study does not offer objective evidence of improved luisitropic properties of the heart, and postoperative magnetic resonance imaging or echocardiographic strain measurements would be helpful in supporting the implication of the manuscripts. Recent studies in patients with LV outflow tract obstruction have demonstrated that surgical relief of obstruction leads to desirable ventricular remodeling, although myocardial fibrosis remains. ${ }^{5}$ One may conjecture those similar mechanisms are at work in the presented patients. All patients

\footnotetext{
From the Division of Cardiothoracic Surgery, Spectrum Health, and Michigan State University College of Human Medicine, Grand Rapids, Mich.

Disclosures: The author reported no conflicts of interest.

The Journal policy requires editors and reviewers to disclose conflicts of interest and to decline handling or reviewing manuscripts for which they may have a conflict of interest. The editors and reviewers of this article have no conflicts of interest.

Received for publication Dec 6, 2021; revisions received Dec 6, 2021; accepted for publication Jan 7, 2022; available ahead of print Jan 12, 2022.

Address for reprints: Tomasz A. Timek, MD, PhD, Division of Cardiothoracic Surgery, Spectrum Health, 100 Michigan Ave NE, Grand Rapids, MI 49503 (E-mail: tomasz.timek@spectrumhealth.org).

JTCVS Techniques 2022;11:29-30

2666-2507

Copyright (c) 2022 The Author(s). Published by Elsevier Inc. on behalf of The American Association for Thoracic Surgery. This is an open access article under the CC BY-NC-ND license (http://creativecommons.org/licenses/by-nc-nd/4.0/).

https://doi.org/10.1016/j.xjtc.2022.01.001
}

underwent initial successful septal myectomy with relief of LVOT gradients and presented for reoperation at a median of 7.1 years. However, it is unclear whether diastolic heart failure was present concurrently with LVOT obstruction or developed over time due to progressive hypertrophy or lack of remodeling, as ventricular dimensions at the time of index myectomy were not provided. Median follow-up of only 0.6 years offers limited insight into the durability of symptomatic relief afforded by the procedure. The coexisting presence of atrial fibrillation in one half of the patients is an obfuscating factor that muddies the waters. As all patients in the study underwent reoperative surgery, it is understandable that addition of a full maze procedure may not be fully justified in this setting, although 2 of the 3 patients underwent pulmonary vein isolation. However, all 3 patients with preoperative atrial fibrillation still felt symptomatically limited by their heart postoperatively, but unfortunately no follow-up of rhythm status was provided in the study. It is recognized that patients with HCM with LVOT obstruction tolerate atrial fibrillation poorly, ${ }^{6}$ and it is not unreasonable to speculate that lack of coordinated LV filling would exacerbate symptoms in these more challenging patients. The persistence of symptoms in patients with atrial fibrillation begs the question of a more aggressive preoperative approach to treatment of rhythm disturbances in these 
highly selected patients or perhaps forgoing the procedure in patients in whom sinus rhythm cannot be reliably reestablished. The subjective end points of the study are a further hindrance for clinical guidance. Three of the patients improved only "some," but it is difficult to ascertain the incremental improvement between "some improvement" and "a lot of improvement" to gauge the clinical significance of residual symptomatology. Again, longitudinal imaging studies and objective functional assessment would bolster the clinical message of the manuscript.

HCM is a heterogenous disease with myriad of phenotypes. The presented patient cohort is so unique it could only come from a center with the largest world experience of surgical treatment of HCM. The Mayo group continues to push surgical therapy of HCM patients to new boundaries, including reshaping of the LV chamber. These challenging patients emphasize the complexity of the disease and need for innovative surgical thought.

\section{References}

1. Kotkar KD, Said SM, Dearani JA, Schaff HV. Hypertrophic obstructive cardiomyopathy: the Mayo Clinic experience. Ann Cardiothorac Surg. 2017;6:32936.

2. Ommem SR, Maron BJ, Olivotto I, Maron MS, Cecchi F, Betocchi S, et al. Longterm effects of surgical septal myectomy on survival in patients with obstructive hypertrophic cardiomyopathy. J Am Coll Cardiol. 2005;46:470-6.

3. Schaff HV, Brown ML, Dearani JA, Abel MD, Ommen SR, Sorajja P, et al. Apical myectomy: a new surgical technique for management of severely symptomatic patients with apical hypertrophic cardiomyopathy. J Thorac Cardiovasc Surg. 2010;139:634-40. https://doi.org/10.1016/j.jtcvs.2009. 07.079

4. Sun D, Schaff HV, Nishimura RA, Gesake JB, Dearani JA, Ommen SR. Surgical management of diastolic heart failure after septal myectomy for obstructive hypertrophic cardiomyopathy. J Thorac Cardiovasc Surg Tech. 2022;11:21-6.

5. Tang B, Song Y, Yang Q, Cui H, Ji K, Zhao S, et al. Changes in left atrial function, left ventricular remodeling and fibrosis after septal myectomy for obstructive hypertrophic cardiomyopathy. J Thorac Cardiovasc Surg. July 8, 2020 [Epub ahead of print]. https://doi.org/10.1016/j.jtcvs.2020.06.017

6. Falasconi G, Pannone L, Slavich M, Margonato A, Fragasso G, Spoladore R. Atrial fibrillation in hypertrophic cardiomyopathy: pathophysiology, diagnosis and management. Am J Cardiovasc Dis. 2020;10:409-18. 